IMAGE

UNAVAILABLE

FOR COPYRIGHT

REASONS

\title{
Pipe dreams
}

\author{
It's a bizarre, toxin-filled microbe that could clean up sewage plants \\ across the globe. Helen Pilcher gets on the trail of the anammox bacterium.
}

$1 /{ }^{\prime}$ hen the good citizens of Delft complained about the smell wafting from the local yeast factory, they had no idea they had initiated the discovery of rocket-fuel-filled bacteria that would mystify microbiologists and force a rewrite of the biology textbooks.

The microbes, known as anammox bacteria, are full of surprises. They flout bacterial convention by having tiny, sac-like compartments. They defy common sense by packing these sacs with toxic hydrazine. And they are helping to resolve a long-standing conundrum about where much of the ocean's ammonia goes. Not content with this, the brightly coloured bacteria are paving the way for environmentally friendly sewage treatments.

The Gist-Brocades yeast factory, situated in the middle of Delft in the Netherlands, was unpopular with the locals because it produced a lot of eggy-smelling, sulphide-rich waste. To keep its neighbours sweet, the company devised an odourless process, breaking down the effluent in sealed, oxygen-free tanks. The pilot plant built in the mid-1980s worked, and sulphide levels fell. But as the residents breathed a sigh of relief, workers at the plant noticed something odd. Dogma had it that ammonia needed oxygen to be broken down so the engineers expected the concentration of that compound in the tank to stay constant. But a few months later, ammonia levels were falling and nitrogen gas was being produced.

Intrigued, the company contacted microbiologist Gijs Kuenen at Delft University of Technology. Kuenen suspected that anaerobic bacteria were at work, combining ammonia with nitrite to form nitrogen gas and water.
The idea that bacteria could use an anaerobic ammonium oxidation or anammox reaction had been proposed some ten years earlier ${ }^{1}$, but most microbiologists were sceptical — no such bacteria had ever been found and the reaction had never been seen occurring naturally.

Kuenen realized that the mysterious Delft bacteria might offer a new method for wastewater treatment and, if found elsewhere, could be important in nature. He decided to investigate $^{2}$. "It was a brave move," says his former $\mathrm{PhD}$ student Marc Strous, now at Radboud University in Nijmegen, the Netherlands. "Kuenen began to study something that all his colleagues thought didn't exist."

\section{Vigorous hybrid}

Electron microscopy helped to nail the suspect. A close look revealed microbes that housed a strange, internal, membrane-bound compartment. This was a big surprise, because only more complex, or 'eukaryotic', cells such as our own are supposed to have such compartments, called organelles. Simpler 'prokaryotic' cells, including bacteria, should lack them. Only one kind of bacterium, the planctomycetes, was then known to play host to such a structure, and it turned out the microbes belonged to this phylum.

Planctomycetes are peculiar because they contain features from all three domains of life - bacteria, eukaryotes and archaea - and some think they may represent an early com-

"We showed it to other chemists and they said it was impossible." - Jaap Sinninghe Damsté mon ancestor. DNA studies place them firmly in the bacterial camp. But their internal organelles make them resemble eukaryotes. And the microbes lack the rigid polymer peptidoglycan in their cell walls, making them similar to members of the single-celled archaea domain. "They blur the definition of what bacteria are," says Strous.

Planctomycetes were not known to perform the anammox reaction, but Kuenen's team incubated the Delft cells with ammonium and nitrite, and watched the ingredients disappear. ${ }^{3}$. Genetic analysis confirmed the microbes' group and they were provisionally named Brocadia anammoxidans; anammoxidans for their unique biochemistry, and Brocadia for their place of discovery and because the bright red bacteria reminded the researchers of gaudy brocade fabric.

In the wake of this paper, colleagues' opinions changed overnight. "This was a real turning point," says microbiologist Mike Jetten, also from Radboud University, who contributed to the work. Before the paper, the majority of microbiologists did not believe that anammox occurred. After it, the theory gained widespread acceptance and anammox bacteria took their rightful place in Earth's nitrogen cycle.

The nitrogen cycle converts stable nitrogen gas into more usable forms, such as ammonia and nitrate ions, and back again, maintaining a global balance (see graphic, overleaf). Nitrogen gas is converted directly to ammonia by nitrogen-fixing microbes, such as those associated with certain plant roots in the soil. Plants and animals consume ammonia, which is released when they die and decompose. The 


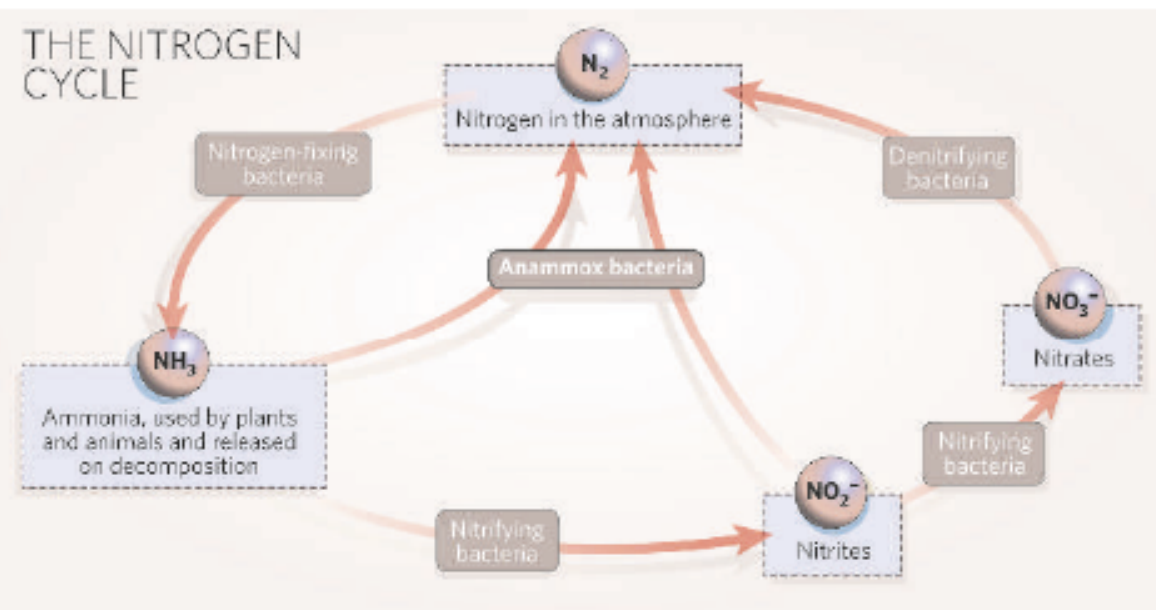

next step is the nitrifying bacteria and archaea, which transform ammonia to nitrites and nitrates, and the cycle is completed as denitrifying microorganisms convert nitrates into nitrogen gas, replenishing the atmosphere. Anammox takes a short cut through the cycle, creating a path from ammonia and nitrite directly to nitrogen gas.

The fact that these bacteria pull off such a stunt is remarkable enough. But when researchers investigated how they did it, there were even more surprises. Findings suggested that the anammox reaction occurring inside the membrane-bound bag, or anammoxosome, produced hydrazine as an intermediate 4 . Why would bacteria produce hydrazine - a potent rocket fuel? The explosive molecule isn't found anywhere else in nature. "We were still puzzled as to what was going on," says Jetten.

\section{Toxic cargo}

It may be that the high-energy hydrazine is needed to drive the anammox reaction. But this does not explain how the bacteria manage their toxic load without killing themselves. Hydrazine can easily diffuse through cell membranes, so Jetten suspected that the anammoxosome membrane must be unusual and in some way able to contain the dangerous load.

He contacted lipid expert Jaap Sinninghe Damsté from the Royal Netherlands Institute for Sea Research in Texel and they analysed the organelle's membrane. What they found was extraordinary ${ }^{5}$. "We showed it to organic chemists at the University of Amsterdam and they said it was impossible," says Damsté.

The membrane's lipids are made of five carbon-based rings fused together to form a dense ladder. This 'ladderane' lipid is peculiar because it has a lot of energy built into it and is very unstable. It is thought the structure makes the membrane exceptionally dense, and so stops hydrazine leaking into the rest of the cell. "It's a complete mystery how nature makes this lipid," says organic chemist and Nobel laureate Elias Corey from Harvard University, who has made the structure in the laboratory. Researchers are now unravelling the bac- terium's genome to work out how it does it. The Dutch team, which has patented the production process for the lipid, hopes that the microelectronics industry will find a use for the impenetrable membrane.

The most pragmatic application of anammox bacteria lies in wastewater treatment. Sewage plants and industrial processes, such as fertilizer manufacture and petroleum refining, generate millions of litres of ammoniarich waste, all of which needs to be broken down. Conventional methods use nitrifying bacteria to convert ammonia into nitrite and nitrate, and then denitrifying bacteria to yield nitrogen gas. The microbes need oxygen, so huge, electricity-gobbling machines are needed to aerate the sludge. And the denitrifying bacteria need an energy source, such as methanol, which they burn to produce carbon dioxide. The process is costly, takes up a lot of space and is unkind to the environment.

Anammox wastewater plants offer major advantages. Anammox bacteria use ammonia as their fuel - there's no need for expensive methanol. They do not need oxygen, so the process uses less electricity. And instead of producing carbon dioxide, anammox bacteria consume it, so the method is environmentally

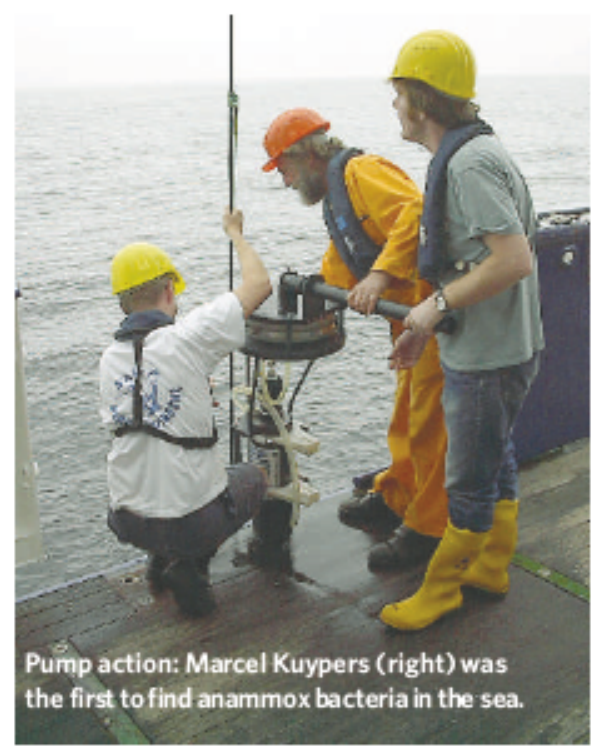

friendly. Altogether, this leads to a $90 \%$ reduction in operational costs and a $50 \%$ reduction in space, compared with conventional methods.

The Dutch company Paques, based in Balk, has developed the first anammox reactor. The prototype has been set up as part of a municipal wastewater treatment plant in Rotterdam and is performing well.

It is likely that anammox will become an important part of wastewater treatment, but its role in the wider world is potentially far greater. Oceanographers looking into anammox reasoned that if the reaction went on in anoxic water tanks, it might also occur in oxygen-poor parts of the sea where it could contribute to the oceanic nitrogen cycle. If that were the case, it would solve a 40 -year-old marine mystery.

In the mid-1960s, Francis Richards from the University of Washington in Seattle noted that ammonia was inexplicably missing in an anoxic fjord ${ }^{6}$. He proposed that it must be being oxidized anaerobically to nitrogen gas, either inorganically or by some unknown microbe. At the time, oceanographers found the idea preposterous.

But in December 2001, biogeochemist Marcel Kuypers from the Max Planck Institute for Marine Microbiology in Bremen, Germany, and his colleagues went fishing for anammox bacteria in the Black Sea - the biggest anoxic basin in the world.

The team drew samples from between 85 and 100 metres down, where oxygen is absent and ammonia is found only in trace amounts. As suspected, anammox bacteria were present - the first time they had ever been found in the $\operatorname{sea}^{7}$.The microbes are incredibly efficient, and it is thought that anammox bacteria may account for up to half of all the nitrogen production in the world's oceans ${ }^{89}$. This is forcing a major rethink of the global nitrogen cycle and slowly persuading oceanographers that denitrifying bacteria are not the only microbes responsible for nitrogen production.

As acceptance of anammox bacteria grows, so too does their grip on the planet. The microbes are turning up everywhere - in fresh and salt water, open oceans and marine sediments, and in wastewater treatment plants all over the world. "One day you discover a bug," says Kuenen, "then ten years later they turn out to be everywhere and important on a global scale. They may even be hiding in the sewer system under your kitchen sink. Helen Pilcher is a freelance science writer based in London.

1. Broda, E Z Ally.Mikrabiol. 77, 491-493(1977).

2. Van de Graaf, A.A. et al. App Env. Microbial. 61, 1246-1251 (1995).

3 Strous, $M$ et al. Nature 400, 446-449 (1999),

4. Van de Graat, A.A. de Builin, P, Robertson, L. A, Jetten, M.s. M. \& Kuenen J.G. Mirabiobgy143, 2415-2421 (1997)

5. Sinninghe Damsté,J.S.et al. Nature 419, 708-712 (2002)

6. Richards, F.A. in ChemicalOceanography (eds Rillex L P.\& Skirrow, G) 611-645 (Academic, London, 1965).

7. Kuypers, M.M.M. et al. Nature 422,608-611 (2003).

8. Dalsgaand, T. etal. Nature 422, 606-608 (2003)

9. Devol, A.H.Nature 422, 575-576 (2008) 